\title{
Shear resistance of welded inclined bars in rectangular reinforced concrete beams
}

\author{
Noor Suhaida Galip ${ }^{1, *}$, Roslli Noor Mohamed ${ }^{2}$, and Ramli Abdullah ${ }^{2}$ \\ ${ }^{1}$ School of Civil Engineering, Faculty of Engineering, Universiti Teknologi Malaysia, 81310 Skudai, \\ Johor, Malaysia \\ ${ }^{2}$ Senior Lecturer, School of Civil Engineering, Faculty of Engineering, Universiti Teknologi \\ Malaysia, 81310 Skudai, Johor, Malaysia
}

\begin{abstract}
The bent-up bars have not been used as shear reinforcement in beams since the past 40 years or so. In all cases of design and construction nowadays, shear forces are resisted by vertical links only. Some complications in installing the multiple set of bent-up bars, the less opportunity to have sufficient number of bent-up bars due to small number of flexural reinforcement provided at the mid-span of the beams and also the large anchorage required for the horizontal portion of the bars beyond the upper end of the bend could be the reasons behind this. This paper presents the results of tests on five rectangular reinforced concrete beams in which the effectiveness of welded inclined bars (WIB) as shear reinforcement was studied. Two of the beams were controlled specimens, with no shear reinforcement in one, and full design vertical links in another. The other three beams were provided with three different quantities of WIB, measured in terms of area to distance ratio, Asw / S as shear reinforcement in the shear spans. All beams were tested to failure under two point loads with a shear span to effective depth ratio of 2.34, which would ensure that the failure was due to shear unless their shear capacities were larger than the flexural capacity. The performances of the beams were measured in terms of deflection, crack formation, strains in WIB and on the concrete surfaces in the shear region, ultimate loads and failure modes. The results show that WIB alone is capable of carrying the whole shear forces in the beam, and larger shear capacities are achieved with a larger quantity of WIB, and a higher grade of the bars used. The beam with WIB requires $22 \%$ less in the quantity of Asw / S compared to that with vertical links to achieve the same shear resistance. These suggest that WIB can be used as an effective system of shear reinforcement in beams.
\end{abstract}

\section{Introduction}

Shear failures in beams occur under combined shear forces and bending moments. The failures which are characterised by small deflections and lack of ductility are recognised by diagonal cracks near the supports. In some cases the failures are followed by a little

* Corresponding author: $\underline{\text { sce_gss@yahoo.com.my }}$ 
explosion. The little warning prior to failure makes shear failures particularly unnegotiable [1]. It is desirable in the design to ensure that the ultimate strengths of the beams are governed by flexure rather than shear. As concrete has limited capacity in resisting the shear cracks, shear reinforcement is provided. Obviously, any form of reinforcement which crosses the shear cracks would be able to resist shear stress to some extent. Vertical links are the most preferred form of shear reinforcement due to its effectiveness, and convenience in fabrication and installation.

A full theoretical analysis for shear has yet to be developed. Shear behaviour and shear capacity of the beam are determined from tests on specimens similar to the ones used in practice. The shear resistance depends on several factors, such as the amount of flexural steel, compression strength of concrete, type of aggregate and effective depth of the section. The shear capacity of a concrete section without shear reinforcement is given by the empirical expression in EC2 [5] as follows:

$$
V_{\mathrm{Rd}, \mathrm{c}}=\left[C_{\mathrm{Rd}, \mathrm{c}} k\left(100 \rho 1 f_{\mathrm{ck}}\right) 1 / 3\right] b d
$$

with a minimum value of

$$
V_{\min }=\left[0.035 k^{3 / 2} f_{\mathrm{ck}} 1 / 2\right] b d
$$

where, $V_{\mathrm{Rd}, \mathrm{c}}=$ design shear resistance of the section without shear reinforcement

$C_{\mathrm{Rd}, \mathrm{c}}=0.18 / \gamma_{\mathrm{m}}$, with $\gamma_{\mathrm{m}}=1.5, C_{\mathrm{Rd}, \mathrm{c}}=0.12$

$k \quad=1+(200 / d)^{1 / 2} \leq 2.0$

$\rho 1 \quad=A_{\mathrm{sl}} / b d \quad \leq 0.02$

$A_{\mathrm{sl}} \quad=$ area of tensile reinforcement

$b \quad=$ width of the section

It can be seen in both equations (1) and (2) that the shear capacities of the beam depend on the concrete strength and part of the longitudinal reinforcement available at support where the shear force is large.

Vertical links have widely been used as shear reinforcement to carry the shear stresses in beams. The quantity, measured in terms of $A_{\text {sw }} / S$ depends on the scale of the shear force applied; the larger the shear force the bigger is the amount of $A_{\text {sw }} / S$ required. Large $A_{\text {sw }} / S$ indicates a system with a large diameter of links arranged at close distances. In cases where the shear forces are very large, the distance between links becomes very close and causes reinforcement congestion.

Studies have been carried out in an attempt to increase the shear capacity of the links. Sayyad and Patankar [6] carried out a test to study the effect of the links orientation on flexural response of beams with the shear span to effective depth ratios of 0.5 and 1.0. They found that horizontal and inclined links possess larger shear capacities than the conventional vertical links. Calajanni et al [7] suggested that combined vertical and inclined links increased the shear capacity of the beams. This is because vertical links only limits the shear capacity due to the high compression in the concrete stress field. Saravanakumar and Govindaraj [8] also reported improved shear resistance and stiffness as well as reducing the deflection of the beam with combined inclined and vertical links.

A section must possess adequate shear capacity; larger than the applied shear force, so that failure of the diagonal compressive struts do not occur. In other words the maximum design shear force is limited by the ultimate crushing strength of the analogous truss and its vertical component. In the design in accordance with EC2 [5], the shear capacity of the beam is derived from the concrete compression strut analogy. The crushing strength $V_{\mathrm{Rd} \text {,max }}$ of the concrete diagonal strut of the beam is given by 


$$
V_{\mathrm{Rd}, \max }=\left[0.36 b d\left(1-f_{\mathrm{ck}} / 250\right) f_{\mathrm{ck}}\right] /(\cot \theta+\tan \theta)
$$

where $\theta$, the inclination of the compression strut to the horizontal axis of the beam, should be in the range $22^{\circ}$ to $45^{\circ}, \theta=22^{\circ}, V_{\operatorname{Rdmax}(22)}=0.124 b d f_{\mathrm{ck}}\left(1-f_{\mathrm{ck}} / 250\right)$, and $\theta=45^{\circ}$, $V_{\mathrm{Rdmax}(45)}=0.180 b d f_{\mathrm{ck}}\left(1-f_{\mathrm{ck}} / 250\right)$

$$
\text { For } 22^{\circ}<\theta<45^{\circ}, \theta=0.5 \sin ^{-1}\left[V_{\mathrm{Ed}} / 0.18 b d f_{\mathrm{ck}}\left(1-f_{\mathrm{ck}} / 250\right)\right]
$$

If the applied shear force, $V_{\mathrm{Ed}}$ is larger than $V_{\mathrm{Rdmax}(45)}$, the size of the beam should be increased. From the derivation, the amount of vertical links is given by

$$
A_{\mathrm{sw}} / S=V_{\mathrm{Ed}} / 0.78 f_{\mathrm{yk}} d \cot \theta
$$

with minimum links of $A_{\mathrm{sw}} / S=0.08 f_{\mathrm{ck}}^{0.5} b / f_{\mathrm{yk}}$ and the maximum distance between links limited to $S=0.75 d(1+\cot \alpha)$, where $\alpha$ is the inclination of the links to the horizontal.

Another form of shear reinforcement that has widely been used was the bent-up bars. These are part of the flexural reinforcement which is no longer required near the support due to the reduced bending moment, being bent-up to cross the diagonal shear cracks. However, in the last 40 years or so, the use of bent-up bars has been diminishing significantly. Obviously, it looks somewhat difficult to install this type of reinforcement. The other drawback is that in cases where the number of flexural reinforcement at mid span is small, an insufficient amount of this bars are left to be bent-up near the supports. The code of practice requires that the bent-up bars should have a full anchorage length beyond the top of the bent Fig. 1a, makes it really hard to have multiple systems of bent-up bars to carry larger shear force.

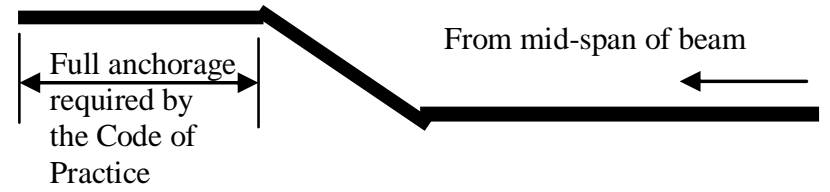

(a) Anchorage requirement beyond the bend

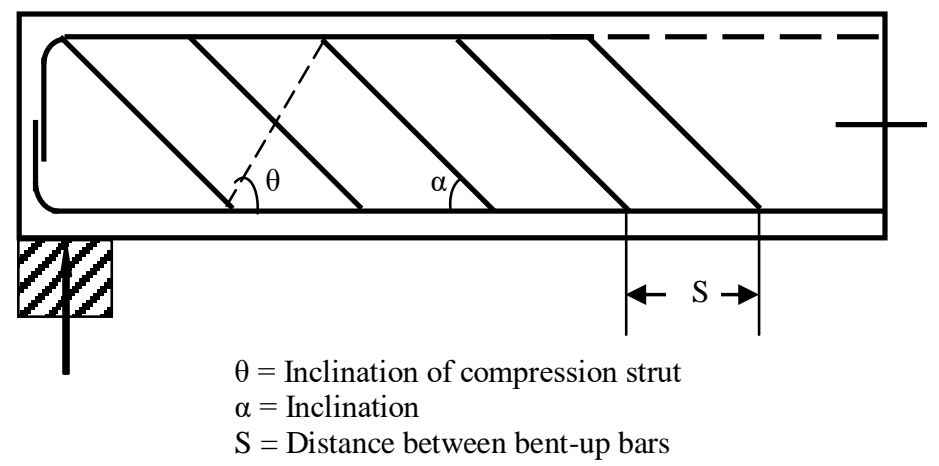

(b) Multiple systems of bent-up bars

Fig. 1. Conventional bent-up bars

The quantity of multiple systems of bent-up bars is given by EC2 [5] as

$$
A \mathrm{~s}_{\mathrm{WIB}} / S=V_{\mathrm{Ed}} / 0.78 f_{\mathrm{yk}} d(\cot \alpha+\cot \theta) \sin \alpha
$$


Where $\alpha$ is the inclination of the bent-up bar to the longitudinal axis of the beam and $\theta$ is the inclination of the variable compression strut. The inclination of the bent-up bars had been taken as $45^{\circ}$, although the more effective one would be normal to the diagonal cracks. Teo and Muller [9] suggested that the shear effectiveness of the bent-up bars depended on the shear span to effective depth ratio based on their investigation on shallow angle bent-up bars. They also recommended that bent-up bars could take up to $75 \%$ of the shear force in a beam, and the minimum inclination of $25^{\circ}$.

Despite the fact that bent-up bars have a high shear capacity, design practice since around the end of 1970's or early 1980's has not been preferred. Most designers had used vertical links only including in cases with quite large shear forces. It was not clear as to why this has happened. The author believes that this has something to do with the adoption of the limit state design since around the end of 1970's locally. Before this period, the design was in accordance with the elastic theory [10] in which the concrete stress was taken as one-third of the characteristic strength, while the steel strength was taken as about half of its characteristic value. With these low material stresses, large amount and hence large number of reinforcement was provided in the beams. Therefore after curtailment, a sufficient number of reinforcement was available to be formed as bent-up bars. However, this has not been the case with the ultimate state design [11, 12]. Adopting larger concrete and steel design stresses, the resulting amount and number of bars provided were smaller, resulting in cases that an insufficient number of bars left to be bent-up. Without the use of bent-up bars, the shear reinforcement was provided by the vertical links only. This has resulted in the use of heavy links in many cases which causes congestion of reinforcement near the support.

The use of independent bent-up bars with insufficient anchorage as shear reinforcement as shown in Fig. 2, have been studied at the Faculty of Civil Engineering, Universiti Teknologi Malaysia [13] which proved to have some shear capacity. As an extension of this work, independent bent-up bars with an anchorage of $50 \mathrm{~mm}$ and inclined links have been studied which produced almost the same findings as the previous study. The test has also showed that this type of shear reinforcement was capable of carrying shear even without any vertical links $[14,15,16]$.

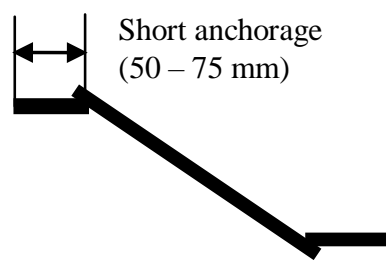

(a) Short anchorage beyond the bend

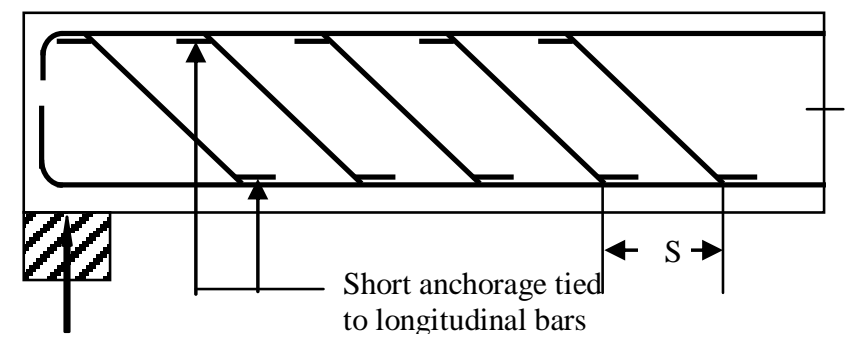

(b) Multiple system of Independent Bent-Up Bars

Fig. 2. Independent bent-up bars

The inclination of the bent-up bars had been taken as $45^{\circ}$, although the more effective one would be normal to the diagonal cracks. Teo and Muller [9] suggested that the shear effectiveness of the bent-up bars depended on the shear span to effective depth ratio based on their investigation on shallow angle bent-up bars. They also recommended that bent-up bars could take up to $75 \%$ of the shear force in a beam, and the minimum inclination of $25^{\circ}$.

Further studies on independent bent-up bars have brought to the experimental investigation on the modified shear reinforcement system $[17,18]$ termed as welded inclined bars (WIB) as shown in Fig. 3. In this system, the inclined bars were welded to the top and bottom holding bars, thus eliminating the need to provide anchorage as in the case with independent bent-up bars. The WIB therefore became a sheet of reinforcement. The studies found that the capacity of the beams in shear was quite large that many of the specimens did not fail in shear but instead they failed in flexure. However, the influence of the quantity of WIB (number and pitch) and the angle of inclination could not be concretely concluded. It should be borne in mind that any test on shear should end up with specimen failure due to shear, so that the influence of variables investigated would be known. This has not been fully observed in the previous test. In fact in some of the specimen tested failure has occurred at the 
welded joint between the incline bars in the top and bottom holding bars. This was because the joints were not properly done; they were only tack welded as shown in Fig. 4.

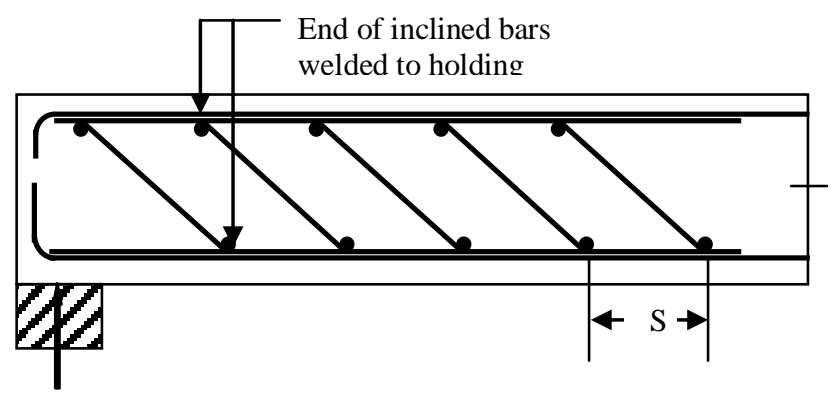

Fig. 3. Multiple System of welded inclined bars

Based on the pilot study on the independent bent-up bars [13], Nasra and Asha [19] and Najmi, Nasra and Asha [20] carried out tests on independent inclined bars which they called swimmer bars, and reported improved shear resistance of about $25 \%$ and crack control compared to the beams using conventional vertical links. The deflection was also reduced by about $14 \%$. Another work on the swimmer bars has also obtained reasonable shear resistance [21]. However the shear reinforcement system used were sheets of welded bars across the width of the beam at certain pitches, which was different from the originally invented system locally [13], where the WIB were sheets of inclined bars in the longitudinal planes.

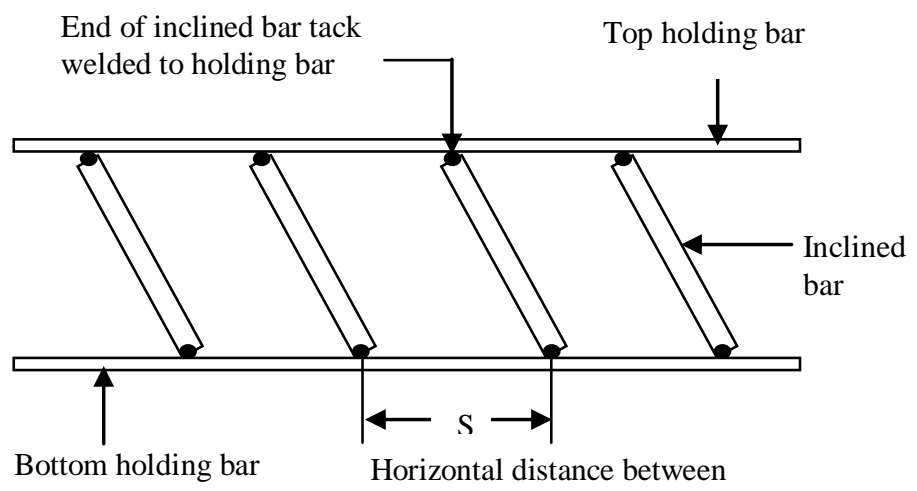

Fig. 4. WIB used in previous tests with the inclined bars tack welded to the top and bottom holding bars.

\section{Experimental program}

\subsection{Specimen Details}

In the present experimental program, five reinforced concrete beam specimens were tested in the Concrete Laboratory of Civil Engineering Faculty, Universiti Teknologi Malaysia. Preliminary design has come up with a beam of $200 \times 270 \mathrm{~mm}$ cross section and $2.4 \mathrm{~m}$ overall length. They were tested on an effective span of $2.05 \mathrm{~m}$, with overhanging of 175 $\mathrm{mm}$ beyond the center-line of the supports. The longitudinal reinforcement consists of $4 \mathrm{H} 16$ at the bottom, arranged in two layers with a vertical gap between layers of $20 \mathrm{~mm}$ 
and hanger bars of $2 \mathrm{H} 12$ at the top. The shear reinforcement in the form of WIB was provided in the shear region at both ends. Typical beam specimen is shown in Fig. 5, and details of the WIB adopted in this study are given in Table 1. Two control beams were also tested; one contained no shear reinforcement, and the other contained full design vertical links.

Table 1. Details of shear reinforcement in the test beams

\begin{tabular}{|c|c|c|c|c|c|}
\hline \multirow{3}{*}{ Beam } & \multicolumn{5}{|c|}{ Shear Reinforcement in Shear Span } \\
\hline & \multirow[b]{2}{*}{ Vertical Links } & \multicolumn{4}{|c|}{ Welded Independent Bars (WIB) } \\
\hline & & $\begin{array}{l}\text { Bar Type } \\
\text { and Size }\end{array}$ & $\begin{array}{c}\text { Inclination, } \beta \\
\left({ }^{\circ}\right)\end{array}$ & Pitch & No. of Sheet \\
\hline B1 & - & - & - & - & - \\
\hline B2 & 2R6-70 & - & - & - & - \\
\hline B3 & - & R8 & 60 & 150 & 2 \\
\hline B4 & - & R8 & 60 & 100 & 2 \\
\hline B5 & - & H8 & 60 & 120 & 2 \\
\hline
\end{tabular}

* In all specimens:

Longitudinal reinforcements are 4H16 (bottom) and 2H12 (top)

The nominal link in the constant moment region R6-150

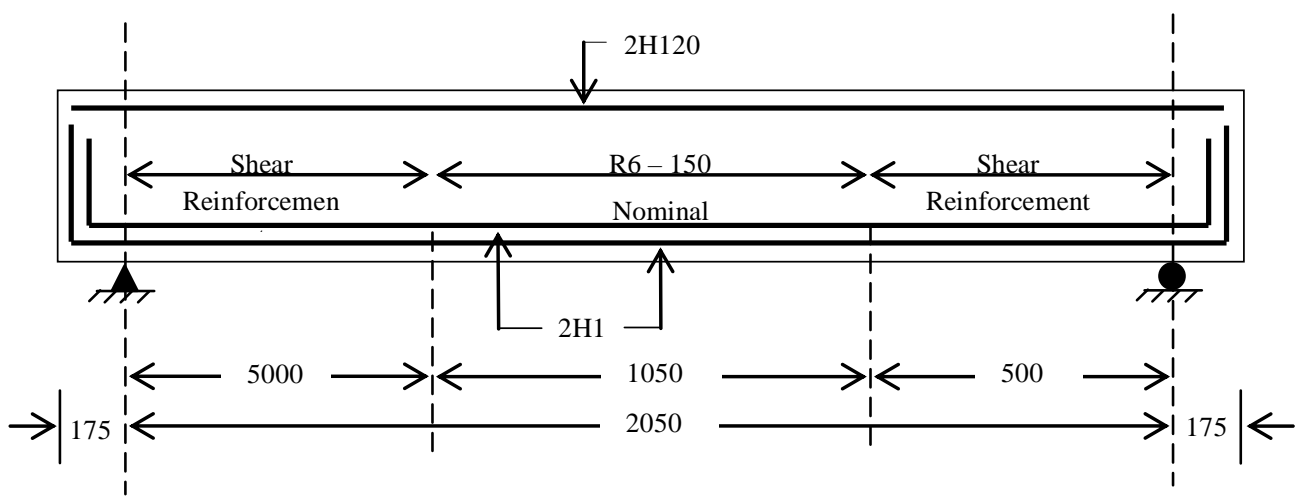

Fig. 5. Typical beam specimen

\subsection{Preparation of Reinforcement Cages}

The main reinforcement and the hanger bars were cut to the required lengths. The H16 bars were then bent at both ends using the bar bender, with a bend radius of four times the diameter, while the hanger bars, H12 were left straight. Links made of R6 were formed manually to the required shape and size. The reinforcement cage for each beam was carefully prepared by fixing the nominal links in the constant moment region and one link each at the ends of the cage. Welded inclined bars for Beams B3, B4 and B5 were then prepared. Inclined bars R8 for Beams B3 and B4, and H8 for Beam B5 were cut to the required length. They were then welded at both ends at the correct pitches to the top and bottom holding bars made from H12 bars. After the completed WIB sheets had cooled off they were dropped from a height of around $2 \mathrm{~m}$, and no damage or broken weld was noted. Fig. 6 shows samples of the compacted WIB sheets.

Two sheets of WIB were then carefully placed in the shear span at both ends of the related beams. Their top and bottom holding bars were tied to the top and bottom 
longitudinal bars respectively as shown in Fig. 7. Electrical strain gauges were earlier fixed on one of the inclined bars in each of the WIB sheets.

\subsection{Casting and curing}

Before placing the reinforcement cages in the moulds, the inner surfaces of the plywood moulds for all beams were oiled. Reinforcement cages for were placed carefully in the moulds. All five beams were cast simultaneously with concrete of Grade C20/25 bought from local ready mix manufacturer. The concrete was placed in two layers, and each layer was properly compacted using poker vibrator. The top surface of the beams was levelled off and smoothed using trowels. Control specimens consisting of 15 cubes and three cylinders were also prepared and compacted in the same manner done for the beams. Plastic sheets were used to cover all the specimens. The moulds for the control specimens and the walls of the mould for the beams were stripped off the following day. They were all cured by spraying little moist and re-covered with the plastic sheets.

\subsection{Test method}

Three days prior to testing, the top and side surfaces of the beams were applied with white emulsion so that detection and marking of the crack were easier as shown in Fig. 8. A day before testing the concrete electrical strain gauges were fixed on the concrete surfaces in the shear spans of all beams.

The position of the supports and applied load were marked using the permanent black marker. Preparation for the test were carried out by placing the sample in the test rig. All related instruments such as loading jack, load cell and linear variable displacement transducers were fixed in positions as shown in Fig. 9. These instrument and strain gauges were then connected to the data logger and computer for recording the loads and various responses during the test.

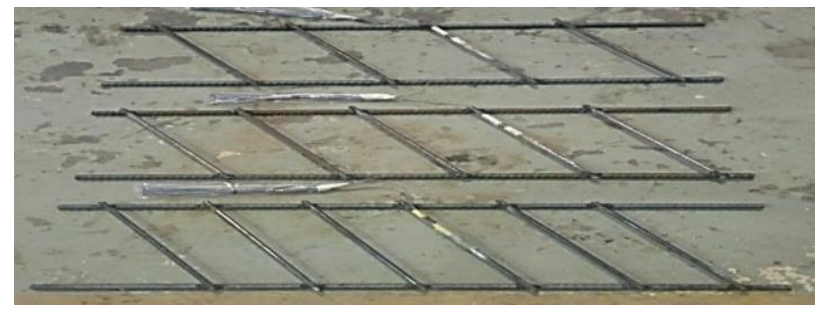

Fig. 6. Samples of welded inclined bars (WIB), R8-150 (Top), H8-120 (Middle) and R8-100 (Bottom) 


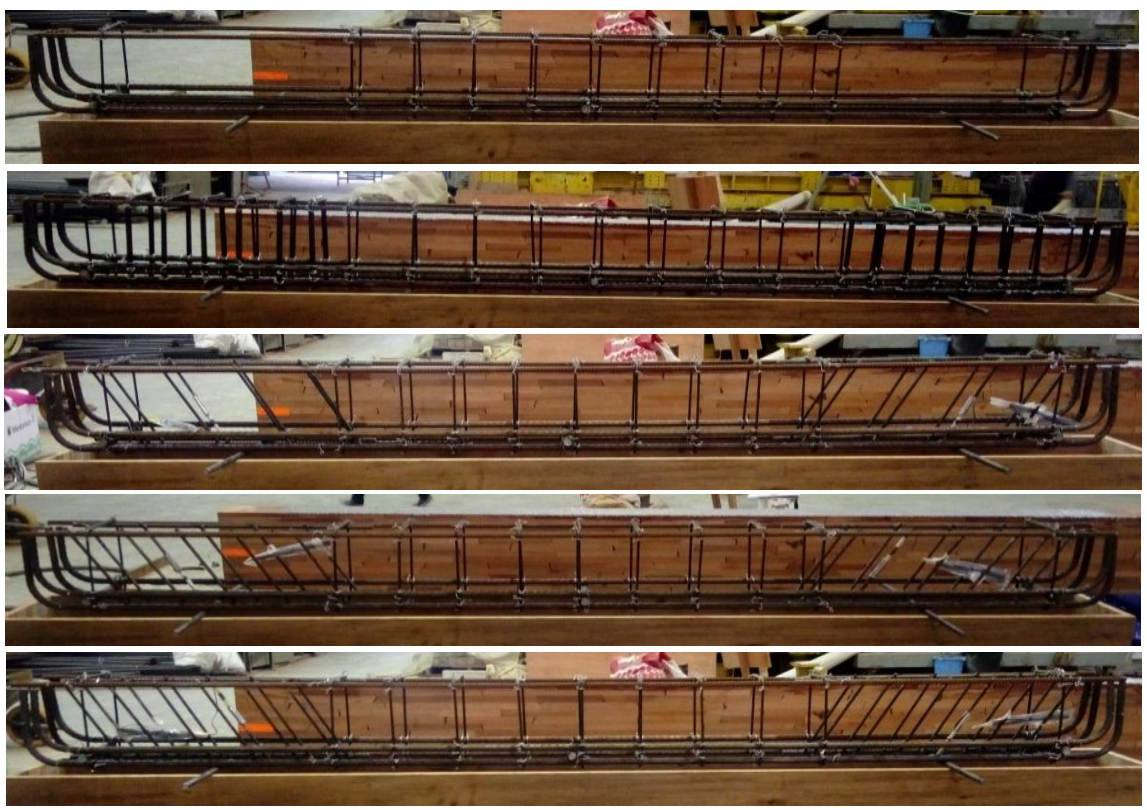

Fig. 7. Reinforcement cages for the five beam specimens: top to bottom - Beams B1, B2, B3, B4 and B5.

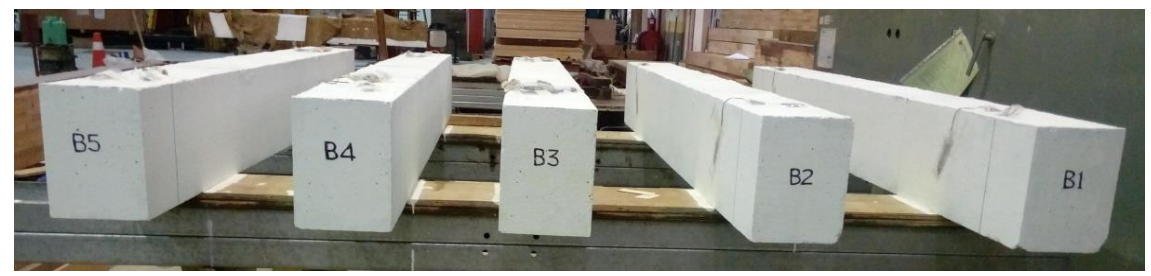

Fig. 8. The beams applied with white emulsion
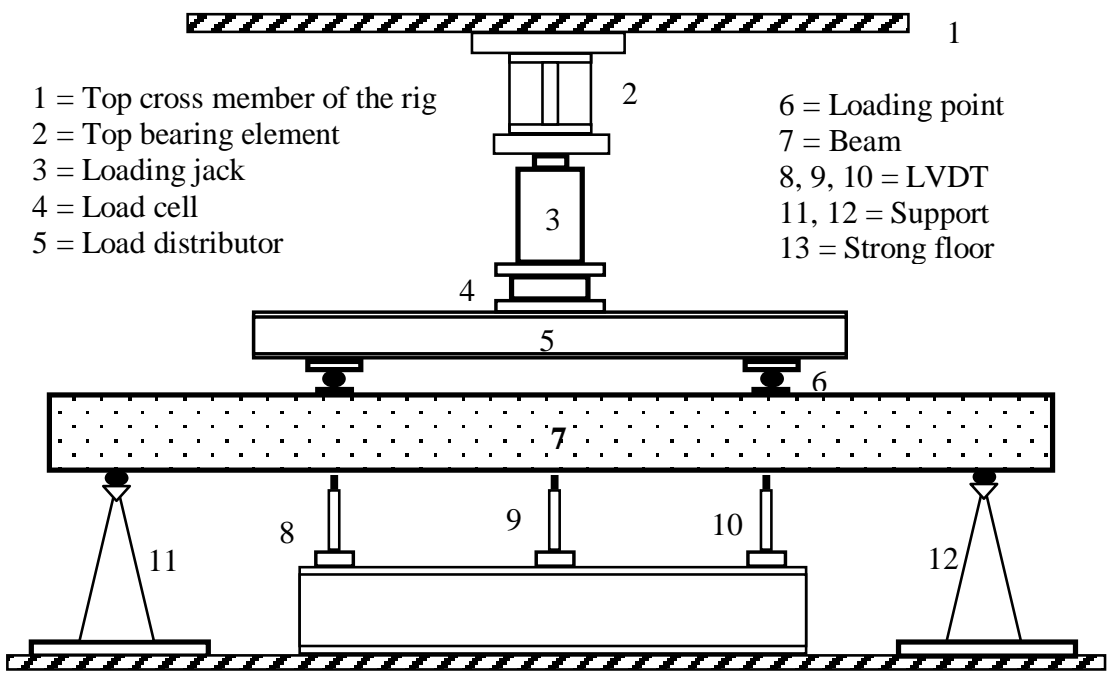

Fig. 9. Typical test set-up 


\section{Analysis of results and discussion}

In all beams, the first crack originated at the bottom face in the constant moment region at a load of around $10 \%$ to $47 \%$ of their ultimate loads. When first spotted, some specimens had one or two cracks while in other specimens four or five cracks occurred simultaneously. Further loading caused more crack along the moment region, and the previous cracks extended in almost vertical direction. Vertical cracks were also seen in the shear spans close to the moment region in most of the beams. However, the propagation of these crack was rather slow compared to those in the constant moment region. At a load of around $60 \%$ to $80 \%$ of their ultimate values, diagonal cracks appeared in the shear spans of Beams B1, B3 and B4. These diagonal cracks were first occurred around the mid-depth of the beam and propagated towards the supports and the point of the applied loads as the load increased. In other beams, the cracks commenced at the supports and extended towards the position of the applied load. Beams B1, B3 and B4 reached the ultimate load due to the diagonal splitting of the concrete in the shear spans, which occurred suddenly and accompanied by a loud bang. Beams B2 and B5 on the other hand failed due to excessive deflection, without diagonal splitting of the concrete in the shear region.

The load versus mid-span deflection curves for all beams are shown in Fig. 10. As can be seen in the figure, Beam B1 has an almost straight line load-deflection relationship, implying the ultimate value was reached in a sudden with a maximum deflection of only $4.8 \mathrm{~mm}$. The other four beams show nearly straight line load-deflection relationships up to about $85 \%$ to $90 \%$ of their respective ultimate loads. After that, Beams B2, B4 and B5 reduced in gradient and continued towards a plateau shape, while that for Beam B3 ended up without similar shape. Strain readings showed that welded inclined bars in Beams B3 and B4 were broken, indicating the bars had reached yielding value. Cracks in the shear spans at failure of Beams B, B2, B3, B4 and B5 are shown in Fig.11. The concrete compressive strength obtained from tests on cylinders and cubes (equivalent average cylinder strength was taken as $78 \%$ of the cube's strength) was $19.5 \mathrm{~N} / \mathrm{mm}^{2}$.

Table 2. Test results

\begin{tabular}{|c|c|c|c|c|c|c|c|}
\hline \multirow{2}{*}{ Beam } & \multicolumn{2}{|c|}{$\begin{array}{c}\text { Shear } \\
\text { Reinforcement }\end{array}$} & \multirow{2}{*}{$\begin{array}{c}\text { Nominal } \\
\mathrm{A}_{\text {sw }} / \mathrm{S}\end{array}$} & $\begin{array}{c}\text { Ultimate } \\
\text { Load } \\
(\mathrm{kN})\end{array}$ & $\begin{array}{c}\text { Ultimate } \\
\text { Shear } \\
(\mathrm{kN})\end{array}$ & $\begin{array}{c}\text { Maximum } \\
\text { Mid-span } \\
\text { Deflection } \\
(\mathrm{mm})\end{array}$ & $\begin{array}{c}\text { Mode of } \\
\text { Failure }\end{array}$ \\
\hline B1 & - & - & - & 105.50 & 52.75 & 4.80 & Shear \\
\hline B2 & $2 \mathrm{R} 6-70$ & - & 1.62 & 313.10 & 156.55 & 22.98 & Flexure \\
\hline B3 & - & $2 \mathrm{R} 8-150$ & 0.67 & 260.60 & 130.33 & 12.78 & Shear \\
\hline B4 & - & $2 \mathrm{R} 8-100$ & 1.01 & 303.60 & 151.80 & 16.84 & Shear \\
\hline B5 & - & $2 \mathrm{H} 8-120$ & 0.84 & 321.10 & 160.55 & 19.41 & Flexure \\
\hline
\end{tabular}

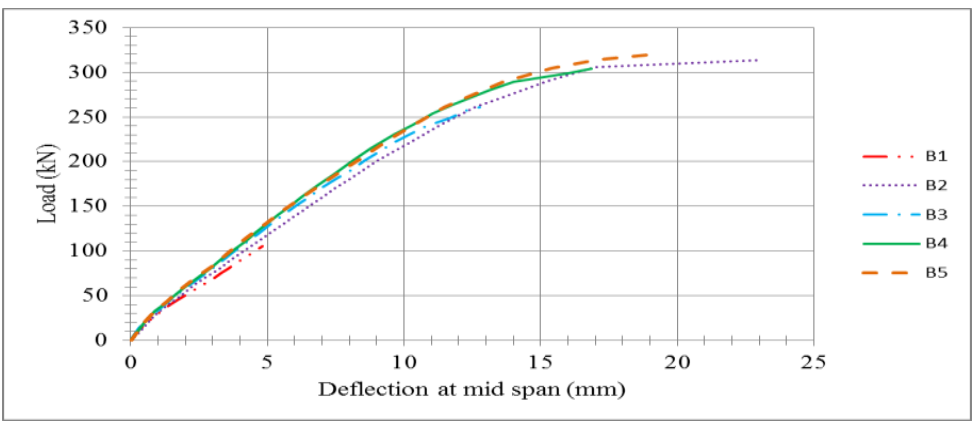

Fig. 10. Load versus mid-span deflection curves for all beams 

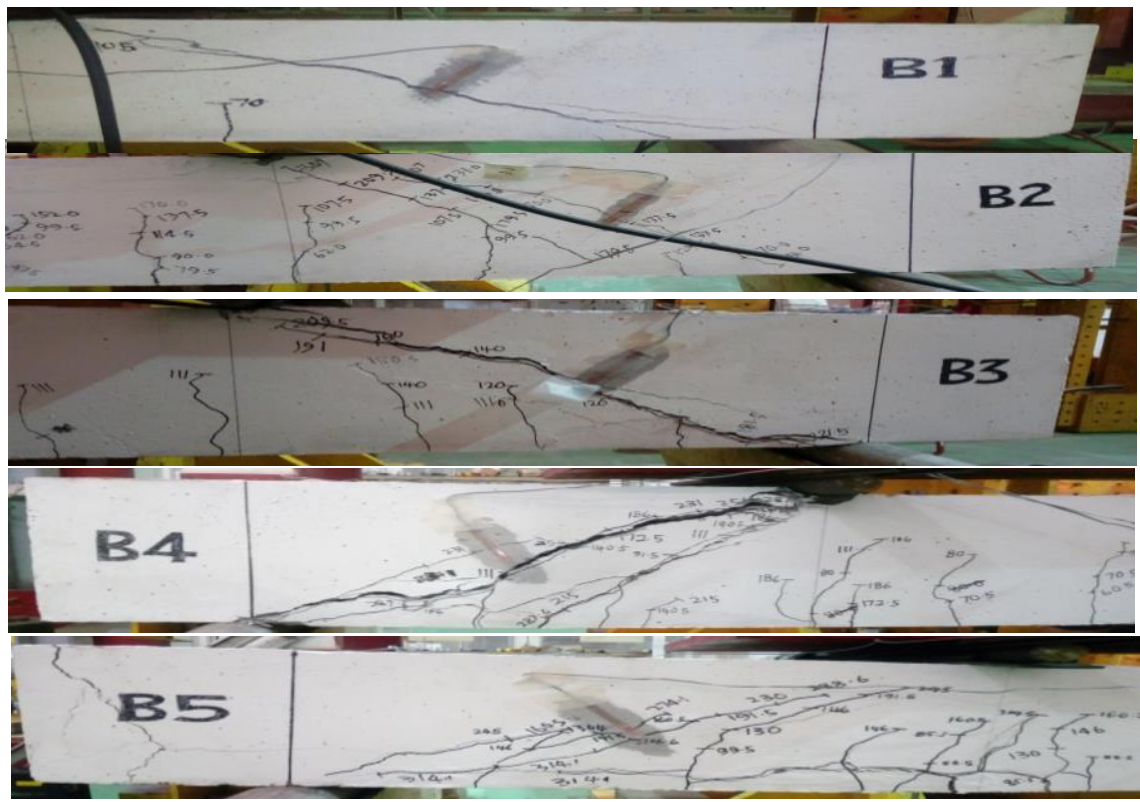

Fig. 11. Crack pattern in the shear span in Beam 1,2,3, 4 and 5 at failure

Beams B1 (without any form of shear reinforcement), B3 and B4 (both with WIB as shear reinforcement) failed in shear as were evidenced by the splitting diagonal cracks in the shear spans. The nearly straight line of their load-deflection curves implies the same and was supported by the broken of the strain gauges in Beams B3 and B4. On the other hand Beams B2 (with sufficient amount of vertical links) and B5 (with high yield steel as WIB) failed in flexure without splitting of concrete in the shear region. Both the beams recorded large mid-span deflection, and the upper portion of their load-deflection curves almost turned a plateau shape, indicating the main reinforcement has yielded.

Beam B1, without shear reinforcement failed at the lowest load, while Beams B2 and B5 with sufficient shear reinforcement in the form of conventional vertical links and WIB respectively achieved the largest ultimate loads. Beams B3 and B4, both with an insufficient amount of WIB achieved the ultimate loads in between the two extremes mentioned above. Comparing the shear capacities of Beams B3, B4 and B5, it is clear that larger quantity of WIB gives larger shear resistance. Although the quantity of the WIB in Beam B5 is almost the same as that in Beam B4, the shear resistance of Beam B5 is not only larger Beam B but is also larger than that of the beam designed with sufficient conventional vertical links (Beam B2). This suggests that larger shear resistance can be achieved when high yield steel is used as WIB.

The strains in the WIB in Beams B3 and B4 show that the WIB has yielded. This indicates that the WIB has fully functioned as shear reinforcement. The strain in the WIB in Beam B5 was considerably large, but did not yield because the beam failed in flexure, which means the shear resistance was large.

Table 3. Calculated Shear Capacity $\left(\mathrm{V}_{\mathrm{Rd}}\right)$

\begin{tabular}{|c|c|c|c|c|c|c|c|c|c|c|}
\hline \multirow{2}{*}{ Beam } & \multicolumn{2}{|c|}{$\mathrm{A}_{\mathrm{sw}} / \mathrm{S}$} & \multirow{2}{*}{$f_{y w}$} & $\theta\left(^{\circ}\right)$ & $\alpha$ & \multicolumn{3}{|c|}{$\mathrm{V}_{\mathrm{Rd}}(\mathrm{kN})$} & Test / & Failure \\
\cline { 2 - 6 } & Nom. & Act. & & & $\left.{ }^{\circ}\right)$ & Design & Test & Cal. & Cal. & Mode \\
\hline B1 & - & - & - & 22.0 & - & - & 52.5 & 49.7 & 1.06 & Shear \\
\hline B2 & 1.62 & 1.3 & 400 & 24.5 & - & 148.0 & 156.6 & 219.3 & 0.71 & Flexure \\
\hline
\end{tabular}




\begin{tabular}{|c|c|c|c|c|c|c|c|c|c|c|}
\hline B3 & 0.67 & 0.53 & 400 & 22.0 & 60 & 74.5 & 130.3 & 108.8 & 1.20 & Shear \\
\hline B4 & 1.01 & 0.80 & 400 & 23.5 & 60 & 105.0 & 151.8 & 153.6 & 0.99 & Shear \\
\hline B5 & 0.84 & 0.82 & 500 & 25.3 & 60 & 163.9 & 160.6 & 184.6 & 0.87 & Flexure \\
\hline
\end{tabular}

Nom. = Nominal (using nominal size of bars)

Act. $=$ Actual (using actual size of bars)

Cal. $=$ Calculated

As can be seen in Table 3, the test and calculated values of shear resistance $V_{E d}$ for the beams which failed in shear are close. For beams which failed in flexure, the test values of $\mathrm{V}_{\mathrm{Rd}}$ are around $13 \%$ to $29 \%$ smaller than their calculated ones. This is because the beams failed in flexure before their shear capacities could be reached.

Figure 3 shows the relationship between the ultimate shear forces in Beams B1, B3, B4 and B5, and their respective quantities of WIB (taken as Nominal $\mathrm{As}_{\mathrm{WIB}} / \mathrm{S}$ ). Since Beam $\mathrm{B} 1$ has no shear reinforcement, the $\mathrm{As}_{\mathrm{WIB}} / \mathrm{S}$ was taken as zero. On the other hand, Beam B5 with $\mathrm{As}_{\mathrm{WIB}} / \mathrm{S}$ of 0.82 was taken as equivalent to 1.68 because it was made from high yield steel $\left(\mathrm{f}_{\mathrm{yk}}=500 \mathrm{~N} / \mathrm{mm}^{2}\right)$, while the WIB in other beams was of mild steel $\left(\mathrm{f}_{\mathrm{yk}}=250\right.$ $\mathrm{N} / \mathrm{mm}^{2}$ ). The curve shows increased shear capacities with increase in the quantity of the WIB but after a stage the benefit from the increase in WIB could no longer be obtained because failure was due to flexure.

A horizontal line representing the shear capacity of Beam B2 of $156.6 \mathrm{kN}$ (provided with conventional vertical link system) was plotted in Fig. 10. From the point where this line intersects the curve, a vertical line was drawn to give the quantity of the WIB required to produce a beam with identical shear capacity as the beam with vertical links. The result gives an Actual $\mathrm{As}_{\mathrm{WIB}} / \mathrm{S}$ value of about 1.27. It may be suggested that if the quantity of the WIB in Beam B4 had been increased from 1.01 to around 1.27, the beam would not have failed in shear but would fail in flexure at a shear force close to $156.6 \mathrm{kN}$ as in Beam B2.

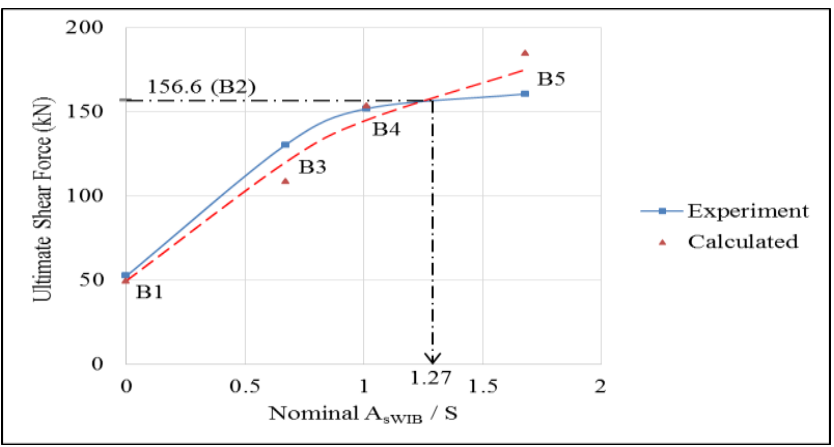

Fig. 15. Ultimate Shear Force versus. Nominal $A_{\text {sWIB }} / S$

\section{Conclusions}

From the investigation reported in this project, the following conclusions can be drawn:

a. Properly manufactured welded inclined bars is capable in resisting the whole shear forces in the beam

b. The shear resistance of the beams increases almost proportionately with the increase in the quantity of welded inclined bars.

c. Welded inclined bars of high yield steel possess larger shear capacity than that of the mild steel at the same amount the area to pitch ratio.

d. At the inclination of $60^{\circ}$ to the longitudinal axis of the beam, the amount of welded inclined bars $\left(\mathrm{As}_{\mathrm{WIB}} / \mathrm{S}\right)$ required to achieve the same shear capacity with the beams 
with conventional vertical links as shear reinforcement is 1.27 and 0.64 for Grades 250 and 500 steel respectively.

The author is deeply grateful to her project supervisor, Dr. Roslli bin Noor Mohamed, Sr. Lecturer in the School of Civil Engineering, Universiti Teknologi Malaysia, for guidance and encouragement received throughout the research. Special thanks are due to Dr. Ramli bin Abdullah for always being ready to help in the laboratory work and giving opinions, comments and ideas on the experimental works. A sincere gratitude is due to the Head of Department of Structures and Materials, for the facilities provided, and also to all the staff of the Department for the knowledge gained.

\section{References}

1 Al-Nasra, M.M., Asha, N.M. (2013). Shear Failure Investigation of Reinforced Concrete Beams with Swimmer Bars, Engineering Journal - Civil Engineering and Construction Technology, vol. 4(2), pp. 56-74.

2 Raju. (2014). Review in Shear Behaviour of Reinforced Concrete Beam without Transverse Reinforcement, International Journal - Engineering Research and Applications, vol.4, Issue 4(Version 8), pp.116-121.

3 British Standards 1997, Structural Use of Concrete - Part 1: Code of Practice for Design and Construction, BS 8110:1997, BSI Publications, UK.

4 Colajanni, P., Mendola, L.L., Mancini, G., Recupero, A., Spinella, N. (2014). Shear Capacity in Concrete Beams Reinforced by Stirrup with Two Different Inclinations, Journal of Engineering, vol. 81, pp. 444-453.

5 Mohamed, H.A., (2017). Effect of Using Swimmer Bars on the Behavior of Normal ang High Strength Reinforced Concrete Beams, Engineering Journal, vol. 8, pp. 29-37.

6 Iskhakov, I., Ribakov, Y., (2014). Exact Solution for Shear Problem for Inclined Cracked Bending Reinforced Concrete Elements, Journal of Engineering, vol. 57, pp. 472-478.

7 S. Najmi, A.Q., Al-Nasra, M.M., M.Asha, N., (2013). Improved Shear Performance of Bent-Up Bars in Reinforced Concrete Beams, International Journal of Engineering Sciences \& Research Technology, Issue 4(Version 5), pp.1264-1268.

8 Arslan, G., Keskin, R.S.O., (2015). Influence of Flexural Reinforcement on The Shear Strength of RC Beams without Stirrups, World Academy of Science, Engineering and Technology International Journal of Civil and Environmental Engineering, vol. 9, No.8, pp. 1036-1041.

9 Saravanakumar, P., Govindaraj, A., (2016). Influence of Vertical and Inclined Shear Reinforcement on Shear Cracking Behaviour in Reinforced Concrete Beams, International Journal of Civil Engineering and Technology, Issue 6, vol.7, pp.602-610.

10 Hemanthkumar, P., Mounika, P., Babu, T.S., (2016). Effect of Swimmer Bars on Reinforced Concrete Beams, International Journal of Emerging Technologies in Engineering Research, vol. 4, Issue 12, pp.66-69.

11 Abdul Hamid, N.A., (2005). The Use of Horizontal and Inclined Bars as Shear Reinforcement, Faculty of Civil Engineering, Universiti Teknologi Malaysia, Master Project, Unpublished.

12 Guan, A.T., (2008). The Influence of the Anchorage of Independent Bent-Up Bars on Its Shear Capacity, Faculty of Civil Engineering, Universiti Teknologi Malaysia, Master Project, Unpublished.

13 Saleh Baras, S.A., (2013) Influence of Independent Bent-Up Bars on the Shear Capacity of Reinforced Concrete Beams, Faculty of Civil Engineering, Universiti Teknologi Malaysia, Master Project, Unpublished. 
14 Sarbini, N.N., (2009) The Effectiveness of Independent Bent-Up Bars with Insufficient Anchorage and Inclined Links as Shear Reinforcement, Faculty of Civil Engineering, Universiti Teknologi Malaysia, Master Project, Unpublished.

15 Mian, K.T., (2016). The Effectiveness of Welded Inclined Bars As Shear Reinforcement in Beams, Faculty of Civil Engineering, Universiti Teknologi Malaysia, Master Project, Unpublished.

16 MALAYSIAN STANDARDS. MS EN 1991: Eurocode 2-Part 1-1 : Design of Concrete Structures - General Rules and Rules for Buildings, MS, 2010 3a. Malaysia National Annex to Eurocode 2. MS,2010.

17 Mosley, W.H., Bangey, J.H., \& Hulse, R., (2012). Reinforced Concrete Design to Eurocode 2, Seventh Edition. Palgrave Macmillan. 